\title{
LOGÍSTICA E TERRITÓRIO
}

Michel Savy ${ }^{1}$

Resumo: Se o transporte de mercadorias não é mais um fator direto de localização das atividades, teria ele perdido sua influência sobre o território? A análise dos fluxos de produtos revela o funcionamento do território como um sistema de zonas interdependentes, no qual o transporte é necessário. A distribuição das infraestruturas, dos empregos e das competências em transporte de frete contribui à diferenciação espacial. O desenvolvimento da logística reforça o papel da circulação de produtos na organização da produção, acentua a importância dos nós na implantação de redes e contribui à polarização espacial das atividades.

Palavras-chave: Localização. Logística. Polarização. Rede. Território. Transporte de Mercadorias.

\section{LOGISTICS AND TERRITORY}

Abstract:The transport of goods is no longer a direct factor of industrial location, but does this mean that it no longer has any influence on spatial organisation? The analysis of traffic flows shows that territory works as a system consisting of interdependent zones, in which transport is necessary. The distribution of infrastructure, employment and skills in freight transport in its turn contributes to spatial differentiation. The development of logistics reinforces the role of circulation in production management, underlines the importance of nodes in network operation and contributes to spatial polarisation of activities.

Keywords: Location. Logistics. Network. Polarisation. Territory. Goods Transport.

\section{LOGISTIQUE ET TERRITOIRE}

Résumé: Si le transport de marchandises n'est plus guère un facteur direct de localisation des activités, a-t-il perdu toute influence sur le territoire? L'analyse des flux de produits révèle le fonctionnement du territoire comme un système de zones interdépendantes, auquel le transport est nécessaire. La répartition des infrastructures, des emplois et des compétences en transport de fret contribue en retour à la différenciation spatiale. Le développement de la logistique renforce le rôle de la circulation des produits dans l'organisation de la production, accentue l'importance des noeuds dans la mise en oeuvre des réseaux et alimente la polarisation spatiale des activités.

Mots-clés: Localisation. Logistique. Polarisation. Réseau. Territoire. Transport de marchandises.

\footnotetext{
${ }_{1}$ Professor emérito da Université Paris Est. Diretor do Observatório de Políticas e Estratégias de Transportes na Europa. Email: savy@univ-paris12.fr

2 Universidade Federal de Santa Catarina (UFSC), Departamento de Geociências, Florianópolis, Brasil, wander_unesp@hotmail.com, https://orcid.org/0000-0002-1017-9070
} 


\section{Introdução}

O transporte de produtos é uma indústria (no sentido de atividade manufatureira) na medida em que transforma diretamente as características físicas dos produtos transportados (suas coordenadas no tempo e no espaço) e lhes incorpora um valor adicional. Se a parcela do transporte produzida sob o regime de transporte público, por conta de outrem, é comumente designada como "serviço", é porque o transportador é um industrial que não possui os produtos que ele transforma: ele vende uma produção e não um produto. $E$, como qualquer outra produção manufatureira, o transporte não se armazena. O transportador contratado tem o estatuto econômico e jurídico de fabricante face a seu carregadorcomandatário.

Devido à massa importante de transporte privado por conta própria, a atividade de transporte de frete ultrapassa largamente o campo coberto pelas noções de setor ou de ramo de transportes nas contas nacionais. O frete stricto sensu emprega, de fato, cerca de 800 mil pessoas na França, 1.500 .000 se adicionarmos os empregos de manutenção e armazenagem, vários milhões se definimos o setor de transporte contabilizando também os empregos ligados à construção e manutenção de veículos e de infraestruturas, à energia, aos seguros, à administração, etc.!

A questão das relações entre a circulação física dos produtos - o "transporte de mercadorias" - e a organização do espaço está no centro de debates científicos há muito tempo. Ela também pode ser abordada a partir de um importante material empírico, que permite reexaminar os modelos teóricos e atualizar o papel dos transportes na organização do espaço. Para tratar do território, o mapa é um meio de representação que se impõe, de modo a ter informações homogêneas e suficientemente detalhadas. Neste artigo, os dados processados contemplam 0 território francês e suas regiões, mas os mecanismos identificados abrangem certamente um espaço europeu mais amplo.

\section{Economia espacial e transporte de mercadorias}

$\mathrm{Na}$ literatura dos fundadores da economia espacial, o transporte era um fator primordial, senão exclusivo, da organização do espaço, quer se tratasse da especialização do solo agrícola em torno dos mercados consumidores urbanos (levando em conta tanto o custo do transporte de produtos quanto sua natureza 
perecível), quer se tratasse da localização das indústrias (minimizando a soma dos custos de transporte de abastecimento e distribuição). Os círculos concêntricos de Von Thünen ${ }^{3}$ e o triângulo de Weber ${ }^{4}$ são figuras emblemáticas desta história do pensamento da economia espacial.

Nos trabalhos contemporâneos, o fator transporte de produtos quase desapareceu nas explicações propostas para compreender as reestruturações do espaço. Exceto para alguns ramos de atividade "pesados", manipulando grandes volumes de produtos de baixo valor específico, o custo de transporte representa uma reduzida parcela do custo total de produção, tornando-se quase um parâmetro indiferente em matéria de localização, ofuscado por outras preocupações: diversidade e dinamismo dos mercados de trabalho, ligações entre serviços e indústrias, inovação, etc.

O sistema de transporte tornou-se verdadeiramente tão eficaz e barato que poderia submeter-se sem restrições à todas as solicitações e localizações de atividades usuárias dos transportes? Políticos e planejadores sempre invocam os "efeitos estruturantes das infraestruturas" para justificar algumas ampliações das redes. Mesmo se a medida das externalidades da produção do transporte esteja confrontada à grandes dificuldades teóricas e metodológicas, é aceito que a disponibilidade de infraestruturas e serviços de transportes é uma condição necessária - mas não suficiente - do desenvolvimento econômico regional: os efeitos estruturantes da infraestrutura essencialmente manifestam-se sobre as zonas deixadas "de fora"5! As escalas de tempo a serem levadas em consideração aqui são muito mais longas do que as do cálculo econômico usual, e as decisões nessa área são uma questão de aposta e de opção política. Frente a essas aparentes

\footnotetext{
${ }^{3}$ Os círculos concêntricos de Von Thünen têm a sua origem no trabalho que o mesmo realizou na Alemanha, em 1820, intitulado "o Estado Isolado". Seu modelo examina a diferença de renda em relação ao mercado, que se torna um paradigma para todas as teorias posteriores. A ideia central é que o rendimento varia de acordo com a distância do mercado, de um isotrópico e espaço isolado. Este tipo de renda é chamado de renda de localização. Von Thünen reconheceu que o homem tenta resolver seus problemas econômicos em seu entorno imediato, reduzindo seus deslocamentos ao mínimo (nota inserida pelo tradutor).

${ }^{4}$ No triangulo de Weber três fatores influenciam a localização industrial. Estes fatores são os dois fatores gerais regionais dos custos de transporte e da mão de obra, e o fator local das forças aglomerativas ou desaglomerativas. Ele primeiro examina a maneira pela qual o ponto de mínimo custo de transporte pode ser encontrado, e então examina as circunstâncias nas quais as vantagens de mão de obra ou de aglomeração operarão. Os custos de transportes são vistos como o determinante primário da localização industrial. Os custos não são considerados diretamente, entretanto, mas como uma função do peso a ser transportado e a distância a ser percorrida (nota inserida pelo tradutor).

${ }^{5}$ Por zonas deixadas "de fora" podemos compreender os espaços com baixa interatividade, no qual as redes técnicas são praticamente inexistentes ou pouco densas, se comparadas com outras parcelas do território (nota inserida pelo tradutor).
} 
contradições, como avaliar o papel atual do transporte de mercadorias na organização do território, o lugar da economia do frete na economia espacial?

\section{O frete: revelador do território.}

A circulação de produtos no espaço é um poderoso revelador das especializações e das interdependências que organizam o território. As trocas alimentam-se das diferenciações espaciais - um espaço homogêneo não geraria nenhum fluxo - e contribuem para fortalecê-las. As diferenças entre zonas afetam tanto a produção quanto o consumo, final ou produtivo.

A abertura dos espaços regionais ao seu ambiente imediato ou distante está longe de ser uniforme. Ela depende das estruturas de produção locais, e também do peso econômico e demográfico de cada região considerada: uma região economicamente diversificada encontra mais, no interior de seus limites, as provisões que ela necessita e os meios para escoar seus produtos do que uma região muito especializada; e uma tal polivalência frequentemente caracteriza mais uma grande região do que de uma pequena.

Antes de examinar os fluxos comerciais entre as regiões, convém, contudo, ressaltar a importância dos tráfegos locais, de curta distância: dois terços das toneladas carregadas e descarregadas não cruzam os limites de uma região administrativa francesa, a distância média de transporte (todos os produtos e modais reunidos) é inferior à $100 \mathrm{~km}$. As relações entre frete e território são, antes de mais nada, centenas de milhões de toneladas de produtos pesados, a granel, transportados a curta distância por rodovia, sob o regime econômico do transporte privado (por conta própria), e que constituem a irrigação econômica fundamental do território. Mesmo se considerarmos apenas os fluxos inter-regionais, que atravessam os limites regionais, constataremos que a maioria deles ligam regiões vizinhas, com exceção de alguns tráfegos que saem ou chegam à região Ilha-da-França ${ }^{6}$, cujo peso econômico no dispositivo de transporte suscita trocas importantes com outras zonas, mesmo distantes.

\footnotetext{
6 Ilha de França (em francês: Île-de-France) é uma das 27 regiões administrativas da França. Sob o Antigo Regime, era uma província francesa. Após a Revolução passou a chamar-se Região Parisiense até 1975, quando recuperou o antigo nome. A Região da llha de França é composta por oito departamentos: Sena e Marne, Yvelines, Essonne, Val-d'Oise, Vale do Marne, Altos do Sena, Seine-Saint-Denis e Paris. Suas principais cidades são: Paris, Pontoise, Versalhes, Évry, Melun, Nanterre, Bobigny, Créteil, Montmorency, Mantes-la-Jolie, Saint-Germain-en-Laye, Rambouillet, Palaiseau, Étampes, Meaux e Argenteuil. Muitas vezes a região é confundida com a Aglomeração Parisiense - que abrange apenas os departamentos de Seine-et-Marne, Yvelines, Essonne e Vald'Oise, e cuja área corresponde a $20 \%$ da Região de Île-de-France, embora concentre $90 \%$ da sua população (nota inserida pelo tradutor).
} 
Na França, observamos que todo um conjunto de regiões contíguas tem uma extroversão econômica confirmada: são as regiões do nordeste do país, ao mesmo tempo mais industrializadas do que as outras e mais próximas da densa zona da Europa Ocidental, onde se concentram população, produção industrial e trocas.

Mas as trocas entre zonas econômicas não se enquadram apenas no esquema de especialização elaborado por Ricardo ${ }^{7}$ para o comércio internacional, com seu clássico exemplo de Inglaterra e Portugal, de um comercio recíproco a se especializar, um na produção de tecidos, o outro na de vinho. Os circuitos de abastecimento das fábricas a partir de seus fornecedores, pelo eventual intermédio de prestadores de serviços logísticos (PSLs) ou por atacadistas, e as redes, às vezes mais complexas e mais longas ainda da distribuição final, levam alguns produtos a atravessar muitas vezes, em todas as direções, vastas parcelas do território nacional. A análise dos fluxos permite, no entanto, distinguir dois tipos diferentes de cooperação inter-regional: a integração e a complementaridade.

A integração desenha zonas que trocam produtos entre si. $O$ equilíbrio ou 0 desequilíbrio desses fluxos depende um pouco da divisão estatística adotada: uma nomenclatura que agregue um grande número de produtos pode revelar fluxos equilibrados, mas que resultam da superposição de vários desequilíbrios, simétricos, que emergiriam no uso de uma nomenclatura mais detalhada. Em todo caso, para produzir produtos agroalimentares, é preciso consumir produtos agrícolas. A mesma regra vale para os produtos industriais: as trocas entre regiões são intrasetoriais. São as mesmas regiões onde encontramos as mais fortes embarques e recepções dessas famílias de produtos: os mapas correspondentes se sobrepõem bastante.

\footnotetext{
${ }^{7}$ A teoria foi formulada por David Ricardo (1772-1823), que criou uma explicação sistemática no seu livro The Principles of Political Economy and Taxation (1817), obra onde se deu início a análise de comércio internacional, onde este passa a ser regido pelas vantagens comparativas e não pelas vantagens absolutas, como acreditava Adam Smith (1776). Em economia, a teoria das vantagens comparativas (ou princípio das vantagens comparativas) explica por que o comércio entre dois países, regiões ou pessoas pode ser benéfico, mesmo quando um deles é mais produtivo na fabricação de todos os bens. O que importa aqui não é o custo absoluto de produção, mas a razão de produtividade que cada país possui. O conceito é muito importante para compreender a teoria do comércio internacional moderno. Na vantagem absoluta, cada país se concentra em um nicho baseado nestas vantagens, beneficiando-se com a especialização em setores nos quais é mais eficiente, e comercializando os seus produtos com outros países. Pela teoria das vantagens comparativas, mesmo que um país não possua vantagem absoluta, ele pode especializar-se nos setores em que apresenta vantagem comparativa (nota inserida pelo autor).
} 


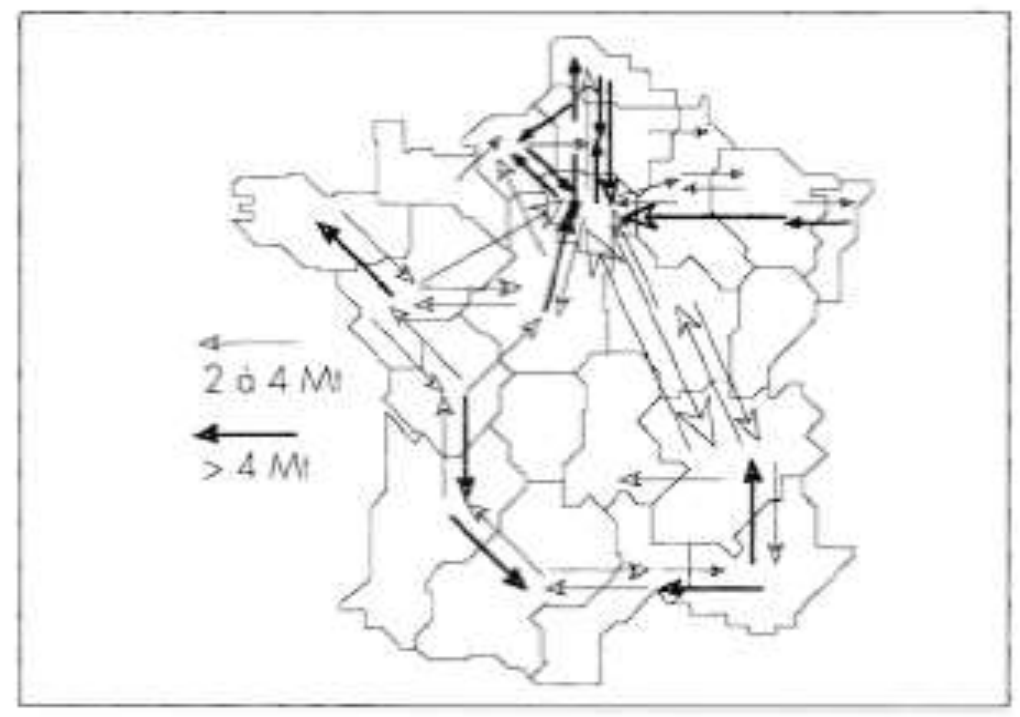

Figura 1: Principais fluxos inter-regionais.

Fluxos de troca inter-regionais, todos os produtos e todos os modais de transportes.

Fonte: Dados SITRAM (Observatório Estatístico e Econômico de Transportes).

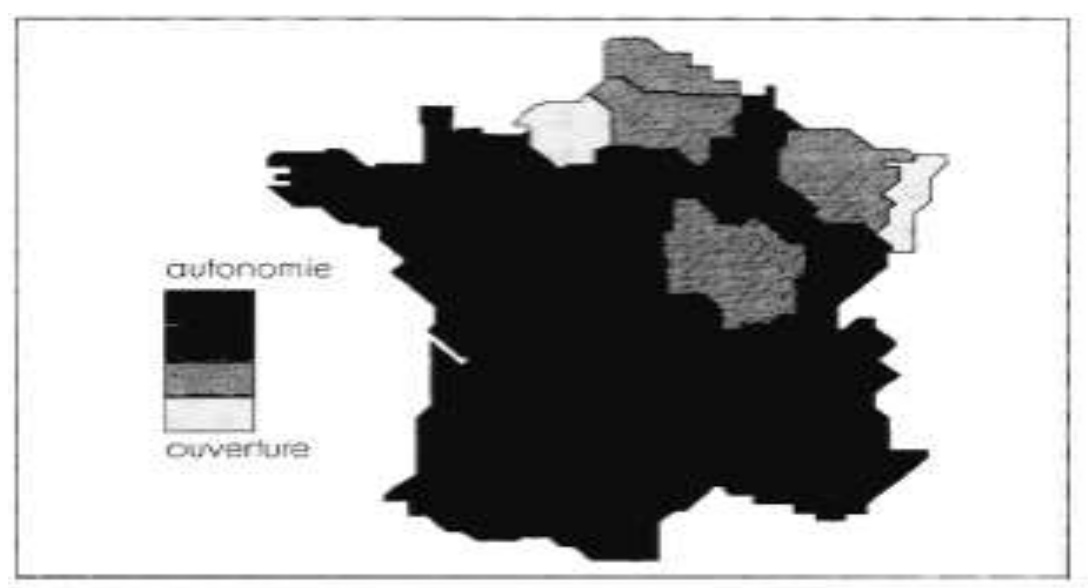

Figura 2: abertura ou autonomia regional.

Relatório de fluxos intra-regionais de todos os tráfegos.

Fonte: Dados SITRAM.
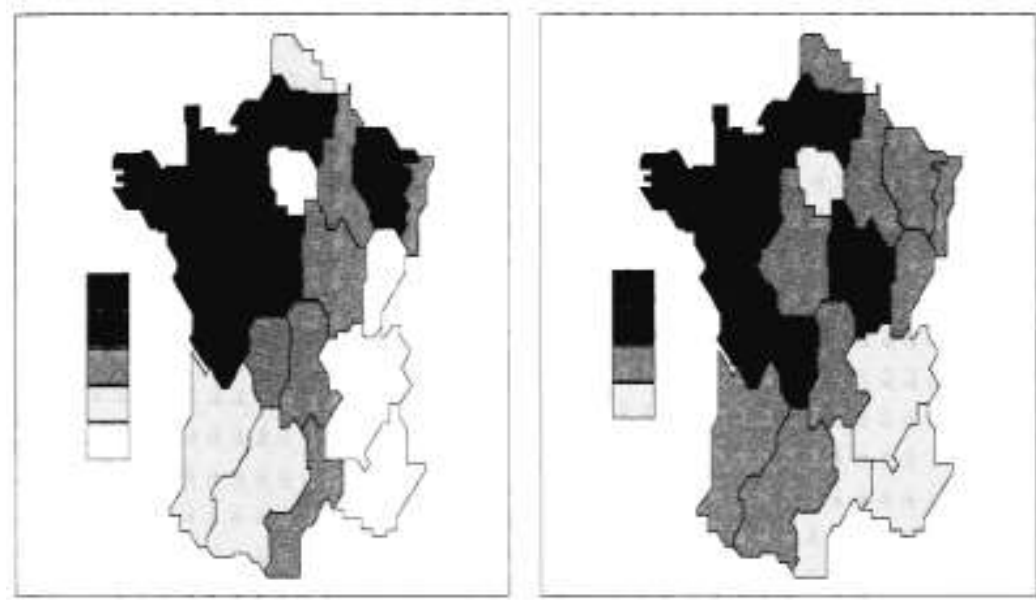

Figura 3: Embarques (à esquerda) e recepções (à direita) de produtos agroalimentares. 
Tonelagem per capita. Fonte: Dados SITRAM.

Em contrapartida, para outras famílias de produtos, a distinção é clara entre as regiões expedidoras e as regiões receptoras: os dois mapas são quase complementares. $\mathrm{Na}$ divisão do trabalho, a relação inter-regional é de complementaridade e não de integração. As trocas inter-regionais são então intersetoriais.

A apreensão do território pelos fluxos que irrigam-no mostra, assim, que as zonas são tão mais interdependentes quão elas são diferentes, que essa interdependência se baseia na integração ou na complementaridade: o território não é uma justaposição de elementos singulares, mas um sistema. A circulação de produtos é uma das principais relações entre os elementos desse sistema. A geografia dos lugares, atenta às localizações, tem na geografia dos fluxos seu duplo.

\section{O frete: uma indústria espacial.}

Se o transporte consiste em "conquistar o espaço pelo tempo", a indústria do frete é, por excelência, uma indústria espacial. Sua geografia é parcialmente ligada à das outras indústrias, usuárias do transporte, mas com uma autonomia tanto mais clara que os meios de transportes são equipamentos produtivos cuja particularidade é ser... móveis.

Uma parte importante do equipamento produtivo do transporte é, no entanto, constituída pelas infraestruturas que são objetos fixos, e cuja criação, manutenção e gestão são, frequentemente, da responsabilidade do Estado. Para compreender a dotação das regiões em infraestruturas de transporte, é conveniente distinguir os níveis de infraestruturas que remetem aos tipos de tráfego e às distintas escalas geográficas. A densidade de estradas departamentais que assegura os fluxos locais é relativamente homogênea no conjunto do território nacional, apesar das variações de densidade demográfica mais acentuadas: a vontade política prevalece, em todas as regiões, para garantir o acesso a todo o espaço regional, quase que independentemente de sua ocupação. Em contrapartida, as infraestruturas capazes de suportar os tráfegos regionais, inter-regionais, internacionais, ou seja as estradas nacionais, as autoestradas, as linhas ferroviárias (as vias hidroviárias, na França, não caracterizam uma verdadeira rede) são estruturadas por eixos e por redes em vez de uma cobertura em área. Elas apresentam uma densidade claramente 
diferenciada de uma região à outra: a lógica econômica pesa aqui mais diretamente sobre as decisões políticas.

Entre as empresas de transporte, podemos opor as atividades de produção de transporte propriamente ditas às atividades de organização dos fretes (comissionários, despachantes, etc.). Umas atuam em todo o território segundo uma densidade com relativo equilíbrio, que também se deve à partilha entre transporte privado e transporte público; outras estão mais concentradas nas regiões metropolitanas do Nordeste do país.
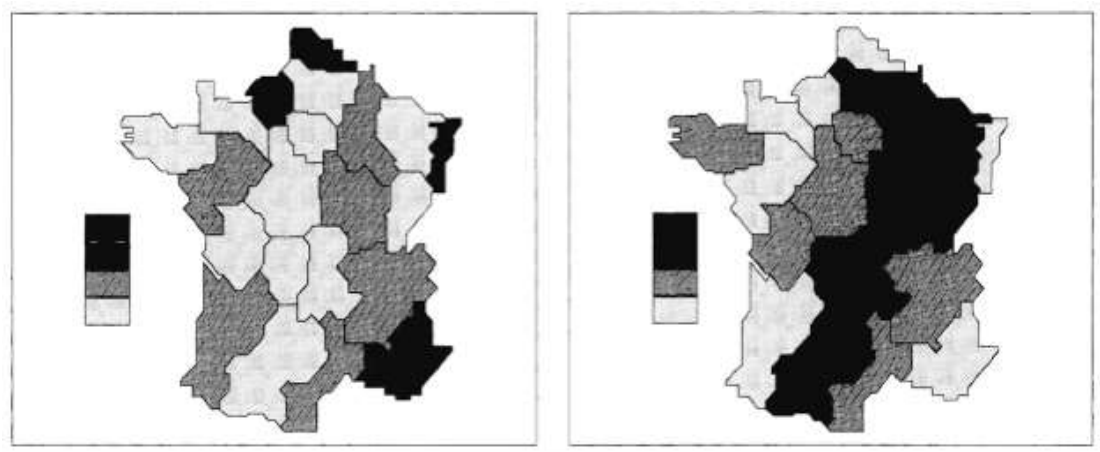

Figura 4: Embarques (à esquerda) e recepções (à direita) de produtos energéticos.

Tonelagem per capita. Fonte: Dados SITRAM.
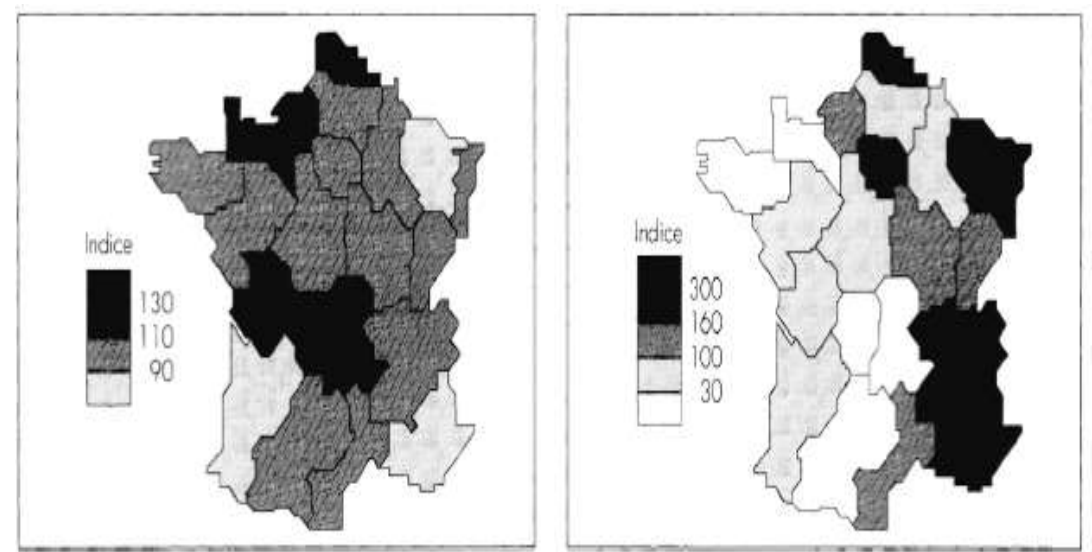

Figura 5: Densidade de estradas departamentais (à esquerda) e auto-estradas (à direita). Índice de densidade ( $\mathrm{km}$ de infraestrutura/ $\mathrm{km}^{2}$ ). Média nacional $=$ Índice 100 .

Quanto à repartição quantitativa específica aos empregos do setor de transportes, a estrutura qualitativa das qualificações é globalmente análoga àquela do conjunto das outras atividades, e aponta para o mesmo esquema de disjunção espacial das funções produtivas entre direção, organização e trabalhos de execução. 


\section{O território das redes.}

As relações entre território e logística são, de fato, mais complexas do que a única questão de localização das infraestruturas e das atividades de transporte. Se a produção de bens materiais é a soma de três componentes, a fabricação, o armazenamento e o transporte, é a interação deles que precisa ser apreendida para compreender a localização das atividades, o funcionamento espacial dos circuitos produtivos e os efeitos do sistema de transporte no território.
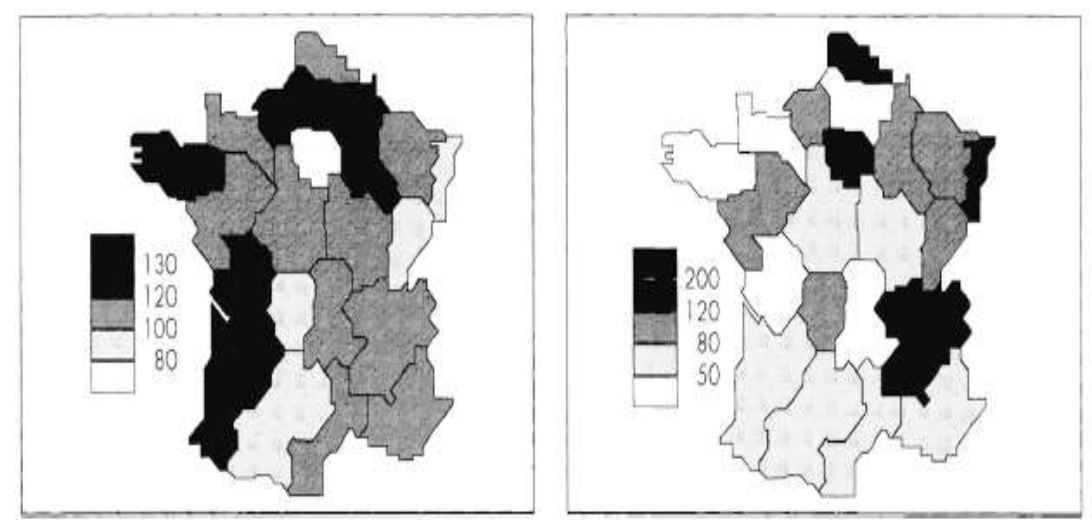

Figura 6: Transporte rodoviário de mercadorias (à esquerda) e embarques de mercadorias de fretes terrestres (à direita).

Índice de especialização regional: parcela do ramo no emprego regional/parcela do ramo no emprego nacional.

Fonte: UNEDIC.
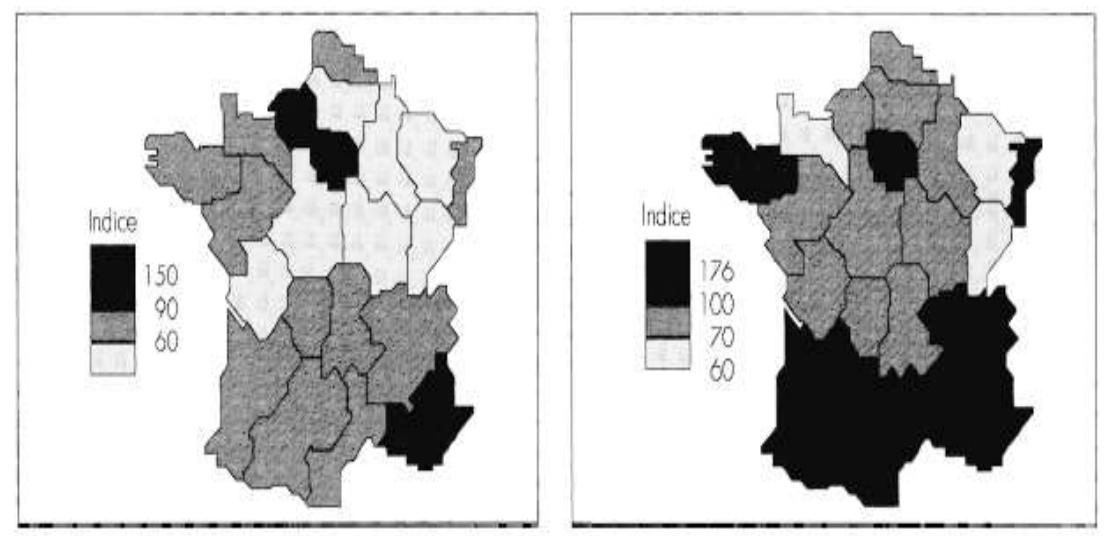

Figura 7: Pessoas ocupadas com a gestão no emprego dos transportes (à esquerda) e no emprego total (à direita).

Índice de especialização Regional: parcela da categoria no emprego regional/parcela da categoria no emprego nacional

Fonte: UNEDIC. 
No movimento de mudança econômica e tecnológica em curso, a gestão da produção atribui um papel primordial aos fluxos de produtos e de informações: gestão dos fluxos para os estoques, para a produção, para a distribuição, para os serviços de atendimento aos clientes, e em breve para o tratamento sistemático de resíduos; gestão por fluxos para a programação da produção em função das aleatórias flutuações da comercialização. Os métodos de "gestão à jusante" (produção orientada pelo mercado), o just in time (JIT), e a diminuição sistemática dos estoques se difundem rapidamente.

As consequências sobre a natureza do frete a transportar são significativas: fragmentação (lotes menores, mais numerosos, fluxos mais aleatórios), maiores exigências em matéria de flexibilidade, de velocidade, de pontualidade, de confiabilidade dos serviços, papel central da gestão da informação, tanto para a gestão do movimento dos objetos quanto para as relações com os clientes. A organização da produção do transporte se transforma pelo uso frequente de técnicas de transmissão de mensagens, visando conciliar fragmentação dos embarques e massificação do tráfego.

Uma divisão técnica e econômica tende a se estabelecer entre o transporte propriamente dito, ao longo das malhas das redes de distribuição, e os nós dessas redes. Essa partilha diz respeito tanto às redes especializadas, adaptadas ao ramo de um usuário particular para abastecer suas unidades de produção ou de vendas, quanto às redes abertas, agregando os carregamentos de múltiplos expedidores. Geralmente, os atores responsáveis pelos pontos nodais controlam todo 0 dispositivo: é nos polos que acontece o processamento estático dos objetos, o controle de qualidade global, e organizam-se as cadeias de abastecimento com seus sub-contratados hierarquizados.

Os efeitos das organizações logísticas e das organizações de transporte sobre o território são complexos, mas significativos, salvo em alguns casos excepcionais, não observamos a localização dos fornecedores nas imediações do estabelecimento de seu cliente, para ser capaz de fabricar e fornecer, a qualquer hora em just in time, as peças requisitadas: não há na Europa equivalente a "ToyotaCity". O JIT pode funcionar à longa distância, desde que os prazos de entrega sejam garantidos.

O movimento acentua, contudo, a concentração espacial: configuração linear das implantações ao longo dos eixos de infraestruturas pesadas, corredores de circulação que oferecem serviços de qualidade confiável; reagrupamento do 
processamento de mercadorias em nós modais e intermodais das redes de infraestruturas e de serviços em plataformas logísticas. Essas plataformas conjugam elementos materiais de equipamento terminal e elementos profissionais de organização. Elas tendem a constituir uma rede hierárquica, conectando os equipamentos que irradiam sobre áreas econômicas de amplitude desigual: local, regional, nacional e europeia.

A diferenciação do território continua, sem dúvida, opondo as grandes regiões europeias, notadamente o centro e a periferia; as o noroeste da Europa beneficia-se de uma posição central em relação aos principais locais de produção e consumo, de uma densa rede de infraestruturas, de uma concentração mais forte de capacidades e competências profissionais no transporte. Mas as diferenciações tendem a organizar-se segundo uma outra morfologia, que não opõe as regiões entre elas, mas sim os polos das redes - estreitamente ligados (mesmo a longas distâncias) -, e os interstícios da rede, deixados de fora pela sua malha: os locais conectados e os outros.

A constituição de um conjunto integrado de atividades complementares voltadas para a circulação física de produtos - a logística - afeta diretamente a localização das empresas de transportes (e dos locais de processamento dos embarques) e de armazenamento, de manutenção, de distribuição, de comércio atacadista, etc. Ela tende a influenciar na localização de unidades manufatureiras para certos produtos de grande consumo (preparação e embalagem). Essas localizações não obedecem tanto à busca pelo custo mínimo de transporte quanto àquela pela facilidade e flexibilidade máximas de circulação dos produtos, para acelerar a rotação e reduzir os estoques. Assim como a gestão à jusante ajusta a conduta da fabricação às flutuações do mercado, a localização do aparelho de circulação dos produtos influencia a do aparelho produtivo. A redução do número de nós na arquitetura dos planos de transportes e do número de entrepostos aumenta a seletividade dessas localizações.

Essas tendencias afetam diversamente as múltiplas categorias de frete considerando a grande variedade da natureza das mercadorias, de seus valores, dos tamanhos e das embalagens de seus lotes, dos circuitos econômicos nos quais elas transitam, etc. No entanto, elas tendem a difundir-se através de modelos organizacionais que propagam as formas de tratar os problemas de uma empresa para outra, de um setor para outro. Por exemplo, as exigências de rapidez e confiabilidade do transporte expresso são aplicadas a certos tipos de tráfego sem 
justificativa econômica clara, à custa da produtividade e do custo do transporte: ou dos valores do transporte: elas contribuem para novas normas de circulação, as quais todos os carregadores e transportadores agora tendem a cumprir.

Essas normas de circulação organizam os dispositivos técnicos e estruturam o espaço. A localização de uma implantação logística num ponto nodal não é sempre imediatamente necessária, sobretudo se os encargos fundiários forem mais caros do que em outros lugares; mas a centralidade do lugar aparece ao investidor como uma garantia de polivalência frente à incerteza do futuro, uma condição de flexibilidade, reduzindo os riscos e multiplicando as possibilidades de adaptação e de reconversão.

Compreendemos assim as várias razões que podem levar as coletividades públicas e as instituições profissionais, como as câmaras de comércio, a apoiar a criação de certas plataformas, com o risco que sua multiplicação resulte em duplicação de esforços e desperdício de recursos. Trata-se de melhor atender a economia local, tanto para seu abastecimento quanto para seus embarques; de fortalecer o quadro dos profissionais do frete; de facilitar-lhes a captação de fluxos para agregar valor aos produtos; de canalizar o tráfego; de organizar o espaço para acolher as instalações logísticas, reduzindo os efeitos nocivos do transporte. Esses dispositivos inscrevem-se, assim, nas ações de desenvolvimento regional, de ordenamento do território e de urbanismo.

\section{Questões e perspectivas.}

Se as evoluções em curso são relativamente bem conhecidas e vigorosas, a previsão do seu desenvolvimento a longo prazo é difícil, considerando os desequilíbrios que aparecerão e as regulamentações inéditas que deverão ser implementadas.

De um lado, a tendência ao crescimento do tráfego e a expansão das redes logísticas continuará, pela expansão de suas ramificações sobre maiores porções dos territórios e pela diversificação da oferta de serviços. O processo de concentração espacial da produção e do armazenamento/distribuição em um número reduzido de locais especializados tende a continuar: ele tem como corolário o aumento das distâncias dos percursos dos transportes, e também do tráfego medido em $\mathrm{t}-\mathrm{km}^{8}$.

\footnotetext{
8 Toneladas por quilômetro (nota inserida pelo tradutor).
} 
De outro lado, o crescimento do tráfego, em especial sobre eixos de infraestruturas pesadas, enfrenta os congestionamentos. A ampliação das infraestruturas tem encontrado maiores dificuldades devido, principalmente, às restrições orçamentárias e às preocupações ambientais: o transporte diz respeito, em primeira instância, à busca por um "desenvolvimento sustentável". As Bocas do Ródano ${ }^{9}$, o Vale do Reno ${ }^{10}$, a Planície Padana ${ }^{11}$ já são sujeitas a tais problemas, que irão agravar, sem esquecer as dificuldades endêmicas das grandes áreas metropolitanas. Todo o território europeu não será igualmente afetado, e as regiões com maior fluidez para a circulação encontrar-se-ão com mais vantagens comparativas. Mas estas dificuldades não seriam contraditórias frente à busca por "fluxos mais densos"?

De modo geral, a tendência histórica de rebaixamento dos custos de transporte, paralelamente com os ganhos de velocidade e qualidade dos serviços, não vai inverter-se? Será que o transporte tornar-se-á uma restrição determinante na tomada de decisões sobre a localização das empresas, na organização de seus circuitos? Uma certa descentralização das manufaturas corrigirá no futuro a concentração em curso?

A multiplicação de grupos de trabalho, de relatórios oficiais e extraoficiais, nos níveis nacional e europeu, reflete uma progressiva conscientização dessas questões. Uma ação original prospectiva, multidisciplinar e internacional, seria necessária para esclarecer as questões, explorar os métodos de avaliação dos projetos a estudar, preparar as políticas regionais, nacionais e europeias de grande magnitude que serão necessárias.

Essas evoluções, e as principais questões a elas relacionadas, reinserem a indústria do frete - a produção de transporte como as infraestruturas - nos debates econômicos, políticos, sociais, científicos, sobre o território. O custo de transporte foi um fator determinante de localização das atividades no século XIX. A logística será, provavelmente, um elemento primordial da organização territorial no século XXI...

\footnotetext{
${ }^{9}$ Bouches du Rhin (Bocas do Ródano) é um departamento da França localizado na região ProvençaAlpes-Costa Azul. Sua capital é a cidade de Marselha (nota inserida pelo tradutor).

10 Le couloir rhodainien (Vale do rio Reno) tem sua nascente nos Alpes suíços e a foz no Mar Mediterrâneo (nota inserida pelo tradutor).

11 La plaine du Pô (Planície Padana) é um dos nomes do território italiano limitado pela ipsométrica dos $100 \mathrm{~m}$, que se estende de oeste a leste daquele país, entre os Alpes a norte e os Apeninos a sul, tendo aproximadamente no centro o rio Pó; o adjetivo "padana" deriva do nome do rio em latim, "Padus". Considerando apenas a parte a sul do rio Ádige, muitas vezes chamada "pianura PadanoVeneta", cobre cerca de $46000 \mathrm{~km}^{2}$, sendo assim a maior planície da Itália; abrangendo as regiões da Lombardia, Veneto, Piemonte e Emilia-Romagna (nota inserida pelo tradutor).
} 


\section{REFERÊNCIAS}

ANDRIEU Henri (1984 et 1986). Atlas des transports de marchandises. Paris: La Documentation française, 2 vol.

AYDALOT Philippe (1976). Dynamique spatiale et développement inégal. Paris:

Economica.

AYDALOT Philippe (dir.) (1984). La Crise de l'espace. Paris: Economica.

BESSON Patrick, SAVY Michel, VALEYRE Antoine, VELTZ Pierre (1988). Gestion de production et transport. Caen: Paradigme.

BOURDILLON Jacques, (rap.) (1992). Les Réseaux de transport français face à l'Europe. Paris: La Documentation Française.

BRAUDEL Fernand (1979). Civilisation matérielle, économie et capitalisme, XVe -XVIlle siècle. Paris: Armand Colin, 3 vol.

BRUNET Roger (1990). Le Territoire dans les turbulences. Montpellier: G1P RECLUS.

BURGUIERE André, REVEL Jacques (dir.) (1989). L Espace français: Paris: Le Seuil

CHAGNAUD Vincent et al. (1987). L'Espace des transports. Paris: OEST.

CHESNAIS Michel (1981). Transports et espace français. Paris: Masson.

CLOZIER Robert (1963). Géographie de la circulation. Paris: M.-Th. Génin.

CIUB EUROTRANS (1992). La Messagerie express en Europe. Caen/Paris:

Paradigme/Presses de l'École nationale des ponts et chaussées.

COLIN Jacques, MATHE Hervé, TIXIER Jacques (1983). La logistique au service de l'entreprise. Paris: Dunod.

COLIN Jacques, SAVY Michel (1990). Logistique et prestation de services. Paris: Éditions Logistiques Magazine.

COLLECTIF (1990). Les Infrastructures de transport: une opportunité de développement. Paris: DATAR.

COMITÉ AMÉNAGEMENT ET LOGISTIQUE EN ILE-DE-FRANCE (1989). Propositions de schéma logistique régional. Paris: Direction Régionale de l'Équipement.

DEMKO George (éd.) (1984). Regional Development Problems and Policies in Eastern and Western Europe. Londres: Croom Helm.

LAJUGIE Joseph, DELFAUD Pierre, LACOUR Claude (1985). Espace économique et aménagement du territoire. Paris: Dalloz.

LEFEBVRE Henri (1972). «La production de l'espace», in Le Droit à la ville. Paris:

Anthropos.

LIPIETZ Alain (1979). Le Capital et son espace. Paris: Maspero. 
MERLIN Pierre (1991). Géographie, économie, planification des transports. Paris: PUF.

PISANI Edgar (1991). Vers une stratégie européenne des transports S.I., 1er mars , 31 p. polygr.

PLASSARD François (1977). Les Autoroutes et le développement régional. Paris:

Economica.

ROWE Frantz, VELTZ Pierre (dir.) (1991). Entreprises et territoires en réseaux. Paris:

Presses de l'École nationale des ponts et chaussées.

SANDOVAL Victor (1987). Fresque sur les transports en France, 1960-1985. Paris:

OEST.

SAVY Michel (1983). «Production des transports et production de l'espace», in Régions et transport de marchandises. Paris: La Documentation française.

SAVY Michel (1993). Logistique et territoire. Montpellier: G1P RECLUS, à paraître.

SAVY Michel, BECKOUCHE Pierre (1985). Atlas des Français. Paris: Hachette.

SAVY Michel, Veltz Pierre (dir.) (1993). Les Nouveaux espaces de l'entreprise. La Tour d'Aiguës / Paris: Éditions de l'Aube / DATAR.

WOLKOWITSCH Maurice (1982). Géographie des transports. Paris: Armand Colin.

\section{NOTAS DO TRADUTOR}

\section{CONTRIBUIÇÃO DE AUTORIA}

Wander Luis de Melo Cruz- Artigo traduzido da versão publicada pela revista L'espace géographique, vol. 22, no 03, 1993, p. 210-218, originalmente em francês. Agradeço a Prof. ${ }^{a}$ Dr. ${ }^{\text {a }}$ Leila Christina D. Dias pela revisão da tradução.

\section{FINANCIAMENTO}

\section{CAPES.}

\section{APROVAÇÃO DE COMITÊ DE ÉTICA EM PESQUISA}

Não se aplica.

CONFLITO DE INTERESSES

Não se aplica.

\section{LICENÇA DE USO}

Este artigo está licenciado sob a Licença Creative Commons CC-BY. Com essa licença você pode compartilhar, adaptar, criar para qualquer fim, desde que atribua a autoria da obra.

\section{HISTÓRICO}

Recebido em: 28-02-2017

Aprovado em: 03-12-2018 